\title{
Monitoramento da presença de Mycoplasma hyopneumoniae em granjas de suínos durante a implementação de programas de erradicação
}

\author{
Monitoring the presence of Mycoplasma hyopneumoniae in swine farms during the implementation \\ of eradication programs
}

\author{
Pablo Jesús Tamiozzo ${ }^{\mathrm{II}{ }^{*}}$ Bibiana Rosa Pelliza ${ }^{\mathrm{I}}$ Alicia Isabel Carranza ${ }^{\mathrm{I}}$ Arnaldo Ambrogi ${ }^{\mathrm{I}}$
}

\section{RESUMO}

\begin{abstract}
O objetivo deste estudo foi monitorar a presença de M. hyopneumoniae em granjas suínas durante a implementação de programas de erradicação utilizando diferentes técnicas de diagnóstico focalizando no PCR. Trabalhou-se com uma empresa que possuía três granjas, uma parto-terminação (390 matrizes), uma múltiplo-sítio (4100 matrizes) e uma nova granja que povoava suas novas instalações. Nas duas primeiras, foi desenvolvido um programa de despovoamento parcial para erradicar a pneumonia enzoótica suína, a última foi povoada pelos suínos dos anteriores após a erradicação. Nos três rebanhos, os suínos foram monitorados por: sorologia (ELISA), PCR, lesões pulmonares macro $e$ microscópicas e a presença de tosse não produtiva. A ausência de tosse, a baixa porcentagem de suínos soropositivos na fase de terminação e a baixa proporção de lesões pulmonares no abate sugerem que a pneumonia enzoótica suína foi erradicada, mas não o agente causativo - M. hyopneumoniae- cujo DNA foi detectado pela PCR, mostrando diferentes comportamentos de acordo com o rebanho.
\end{abstract}

Palavras-chave: Mycoplasma hyopneumoniae, pneumonia enzoótica suína (PES), nPCR, ELISA, lesões pulmonares.

\section{ABSTRACT}

The aim of this study was to monitor the presence of M. hyopneumoniae in pig farms during the implementation of eradication programs using different diagnostic techniques focusing on PCR. They worked with a company owner of three farms, a farrow-to-finish (390 sows), a multiple-site (4100 sows) and a new one that was populated its new facility. In the first two were developed a partial depopulation program to eradicate swine enzootic pneumonia, the latter one was populated with pigs after the previous eradication. In the three farms, the pigs were monitored by: serology (ELISA), PCR, macroscopic and microscopic lung lesions and the presence of non-productive cough. The absence of cough, low percentage of seropositive pigs in the finishing stage and the low proportion of lung lesions at slaughter suggest that swine enzootic pneumonia was eradicated, but not the causative agent -M. hyopneumoniaewhose DNA was detected by PCR showing different behaviors according to the herd.

Key words: Mycoplasma hyopneumoniae, swine enzootic pneumonia (SEP), nPCR, ELISA, lung lesions.

\section{INTRODUÇÃO}

O Mycoplasma hyopneumoniae (M. hyopneumoniae) é o agente etiológico primário da Pneumonia Enzoótica Suína (PES), uma doença respiratória crônica que causa significativas perdas econômicas à suinocultura mundial (THACKER, 2006). Para controlar e erradicar a PES, assim como outras doenças, o método mais eficaz é o despovoamento total seguido de repovoamento com animais livres do patógeno em questão (HARRIS, 2000), mas há outras maneiras econômica e operacionalmente menos dispendiosas, como o despovoamento parcial. O despovoamento parcial tem uma eficácia entre $80 \%$ e $90 \%$ para eliminar M. hyopneumoniae e Actinobacillus pleuropneumoniae (BÆKBO, 2001), sendo amplamente utilizado em todo o mundo.

IDepartamento de Patología Animal, Faculdad de Agronomía y Veterinaria, Universidad Nacional de Río Cuarto, Ruta 36, km 601, CP 5800, Córdoba, ARG, Argentina. E-mail: ptamiozzo@ayv.unrc.edu.ar. *Autor para correspondência.

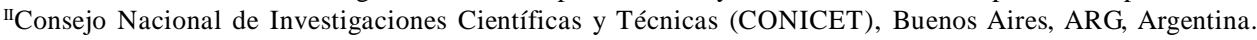


A literatura não é totalmente clara quando se refere ao sucesso destes programas em que faz referência à: tentativa de erradicação (SMITH \& MORTIMER, 2000), erradicação(BÆKBO et al., 1994), tentativa de eliminação (NIELSEN et al., 2002), eliminação (ALFONSO et al., 2004) e exclusão da infecção (KERN et al., 1998). Esta variabilidade nas denominações pode ser devido ao sucesso parcial no desenvolvimento de protocolos em cada caso particular, ou aos métodos de diagnóstico utilizados para o monitoramento desses programas usarem técnicas diferentes com maior ou menor sensibilidade. Para tentar chegar a um consenso, podemos dizer que a erradicação da doença é a ausência de manifestações clínicas e patológicas, porém a erradicação do patógeno é a total ausência deste, fato nem sempre possível.

Quanto às ferramentas diagnósticas para monitorar os programas de controle e/ou erradicação da doença, os sinais clínicos, sorologia e inspeção de lesões pulmonares no abate são as mais utilizadas. A presença de tosse e lesões pulmonares são ferramentas sugestivas. A sorologia, especificamente o ELISA, é o instrumento diagnóstico mais utilizado para determinar a presença de M. hyopneumoniae num rebanho, mas, devido à baixa sensibilidade dos testes de ELISA disponíveis (ERLANDSON et al., 2005), o atraso na resposta imune (THACKER et al., 1998) ou diferentes interpretações dos resultados sorológicos (SIBILA et al., 2004; SØRENSEN et al., 1997) este tipo de teste não deveria ser usado isoladamente, e outras técnicas diagnósticas mais sensíveis poderiam ser usadas conjuntamente. Por isso se faz necessário ou desenvolver técnicas mais precisas ou fazer uso combinado das técnicas disponíveis para identificar corretamente o estado da infecção dos rebanhos e, assim, ser possível responder ao crescente interesse na erradicação da M. hyopneumoniae.

De acordo com THACKER (2007), para implementar estratégias de erradicação de um microorganismo, é fundamental contar com técnicas de diagnóstico capazes de detectar com precisão os animais infectados, por isso a PCR deve ser considerada. Tem sido sugerido que seus resultados devem ser analisados com cautela em condições de campo (THACKER , 2006). No entanto vários estudos relataram resultados significativos usando PCR e sorologia para abordar a dinâmica da infecção (CALSAMIGLIA et al., 1999a; SIBILA et al., 2004) em rebanhos suínos com sinais clínicos, mas nunca havia sido feito no monitoramento de programas de erradicação.

Portanto, levando em conta as diferentes capacidades de testes diagnósticos para a detecção do agente, o objetivo deste estudo foi monitorar a presença de $\boldsymbol{M}$. hyopneumoniae em granjas suínas durante a implementação de programas de erradicação utilizando diferentes técnicas de diagnóstico focalizando na PCR.

\section{MATERIAL E MÉTODOS}

O estudo foi conduzido numa empresa que possuía três granjas. A granja A era um núcleo de genética com 390 matrizes, fornecedor de animais de reposição para a granja B. A granja B se constituía em um múltiplosítio, com aproximadamente 4100 matrizes. Ambas tinham medidas de biossegurança internas e externas e possuíam história de PES (tosse não produtiva e lesões pulmonares no abate, com $76 \%$ dos animais com lesão sugestiva de PES nos pulmões). A granja $\mathrm{C}$ era um novo estabelecimento, múltiplo-sítio, com uma projeção para 12000 matrizes que estava sendo povoado com suínos da granja B.

Para garantir uma população livre de $\boldsymbol{M}$. hyopneumoniae na granja $\mathrm{C}$, a empresa decidiu fazer um programa de despovoamento parcial começando pela granja A, seguindo com a granja B. Por conseguinte, todos os animais menores de 10 meses de idade foram eliminados da granja, o plantel de reprodutores remanescentes (fêmeas adultas, marrãs e machos), foram vacinados pelo menos com cinco doses de vacina contra M. hyopneumoniae (RespiSureONE, Pfizer, Argentina). As coberturas (e nascimentos) foram interrompidas por um período de 14 dias na granja A, e sete dias na granja B. As instalações foram limpas e desinfetadas. Todos os animais que foram mantidos nas instalações receberam alimentação medicada com 100ppm de tiamulina (10\% premix Dinamutilina ${ }^{\circledR}$, Novartis, Argentina) e 300ppm de clortetraciclina (CTC). Em um período de quatro meses, nenhum animal de reposição foi introduzido nas granjas.

Nas granjas A e B, foi feito um estudo longitudinal. Os leitões nascidos após o reinício dos nascimentos (1aㅗ semana) foram considerados progênie livre de PES. Na granja A, um total de 112 animais foram aleatoriamente selecionados e amostrados (com uma semana de intervalo) nas semanas 1, 3 e 5 , depois que os partos foram reiniciados, formando três grupos: Grupo $\mathrm{A}$ $(n=37)$, Grupo B ( $n=36)$ e Grupo C $(n=39)$. Este $n$ representava $50 \%$ da produção semanal. Na granja B, foram amostrados 163 suínos e, da mesma forma que na granja A, também se formaram três grupos: Grupo A $(n=52)$, Grupo B $(n=53)$ e Grupo C $(n=57)$. Este $n$ representava $15 \%$ da produção semanal. Em todos os casos, o $n$ foi calculado com uma prevalência estimada de $10 \%$ para a detecção de pelo menos um caso, com nível de confiança de $95 \%$ e uma precisão de $5 \%$. Os animais que morreram durante o estudo não foram substituídos por outros. 
Foram coletadas amostras de sangue para sorologia (ELISA)e swabs nasais para nested $\mathrm{PCR}$ (nPCR) nas $2^{\mathrm{a}}, 10^{\mathrm{a}}, 15^{\mathrm{a}} \mathrm{e} 21^{\mathrm{a}}$ semanas de idade na granja $\mathrm{A}, \mathrm{e} 2^{\mathrm{a}}, 8^{\mathrm{a}}$, $15^{\underline{a}}$ e $21^{\underline{a}}$ semanas de idade, na granja B. Na granja B, 11 e 16 meses após a aplicação do despovoamento parcial, foram amostrados 100 suínos da fase de terminação de 21 semanas de idade (100 animais em cada amostragem) coletando sangue para sorologia (ELISA).

Na granja $\mathrm{A}$, sendo um núcleo de genética, apenas os animais de descarte foram enviados para o matadouro, razão pela qual os pulmões de suínos dos grupos contemporâneos acima descritos também foram inspecionados. Foram enviados para abate 201 suínos, com idade média de 21 semanas, e os pulmões foram inspecionados procurando pneumonias crânio-ventrais. $\mathrm{Na}$ granja B, suínos pertencentes aos grupos acima referidos foram acompanhados até o abate, examinando um total de 132 pulmões em busca de pneumonias crânioventrais.

Para ocupar as novas instalações da granja $\mathrm{C}$, os leitões da granja $\mathrm{B}$ foram desmamados aos 7-9 dias de idade, tratados com tulatromicina (Draxinn ${ }^{\circledR}$, Pfizer, Argentina) e em seguida levados para as novas instalações da granja C. Nesta granja não foram realizados perfis do nPCR nem perfis sorológicos, e apenas animais da fase de terminação foram considerados (devido aos custos).

Foram amostrados 10 grupos de 100 suínos cada um, com 22 semanas de idade, coletando amostras de sangue para sorologia (ELISA). As amostras de swabs nasais para nPCR foram coletadas apenas dos três primeiros grupos. Por indisponibilidade de algumas amostras, finalmente foram analisadas 987 amostras de soro e 216 amostras para nPCR. Destes, 193 suínos foram seguidos até $\mathrm{o}$ abate, e os pulmões foram inspecionados em busca de pneumonias crânio-ventrais.

Em todos os casos, dos animais que apresentavam pneumonias crânio-ventrais, foram coletadas amostras de pulmão para exame histopatológico (algumas vezes mais de uma amostra por pulmão). Assim, foram analisadas pela histopatologia 44 peças de pulmão de suínos pertencentes à granja $\mathrm{A}, 36$ à granja $\mathrm{B}$ e 19 à granja $\mathrm{C}$. Além de tudo isso, em todos os grupos, os suínos foram observados quanto à ocorrência de tosse, diariamente, durante dez minutos, pelos inspetores treinados.

Tratamento das amostras

Sorologia: A presença de anticorpos contra M. hyopneumoniae foi testada por ELISA (HerdChek ${ }^{\circledR}$ Mycoplasma hyopneumoniae, IDEXX, Maine, E.U.A.) seguindo as instruções do fabricante. Os soros com valores de densidade óptica (DO) superiores ao ponto de corte foram considerados positivos, e os restante (suspeitosos e negativos) como negativos.

nPCR: Os swabs nasais foram ressuspendidos em $1 \mathrm{~mL}$ de água bidestilada estéril e centrifugados a $10.000 \mathrm{x} \mathrm{g}$ durante $10 \mathrm{~min}$ a $4^{\circ} \mathrm{C}$. A partir do sedimento, o DNA foi extraído usando um kit comercial (DNAzol ${ }^{\circledR}$, Invitrogen $\left.{ }^{\mathrm{TM}}, \mathrm{CA}, \mathrm{EUA}\right)$. A cada quinze amostras, um $s w a b$ vazio foi incluído como controle negativo do processo de extração de DNA. O nPCR foi feito de acordo com estudos anteriores (CALSAMIGLIA et al., 1999b), exceto pelo fato de que $5 \%$ de glicerol não foi utilizado. A cada 5 amostras, foi incluído DNA de Mycoplasma floccculare como controle negativo e, a cada 15 amostras, DNA de uma cultura pura de M. hyopneumoniae foi colocado na última posição como controle positivo. Os produtos amplificados (352pb) foram submetidos à eletroforese em gel de agarose $1 \%$, corado com $0,5 \mu \mathrm{g} / \mathrm{mL}$ de brometo de etídio e visualizados Para minimizar o risco de contaminação, cada etapa do processo (extração de DNA, PCR e electroforese) foi feita em salas separadas.

Histopatologia: Após a fixação em formalina tamponada a $10 \%$, as amostras de pulmões foram desidratadas, incluídas em parafina, secionadas a $4 \mu \mathrm{me}$ coradas com hematoxilina-eosina para exame histológico. As lesões histopatológicas foram classificadas (de 0 a 4 ) seguindo o critério de CALSAMIGLIA et al. (2000). Somente foram consideradas como lesões compatíveis com PES aquelas que tiveram uma pontuação de três ou quatro graus na escala proposta.

\section{Análise estatística}

Para a análise estatística, foi utilizado o programa EPIDAT (Versão 3.1, Galiza, Espanha). Foram comparadas as proporções de suínos nPCR positivos da seguinte forma: Nas granjas A e B foram comparadas as proporções de animais nPCR positivos nas $2^{2}, 8^{\mathrm{a}}-10^{\mathrm{a}} \mathrm{e}$ 15aㅗ semanas de idade, e as proporções de animais nPCR positivos obtidas nas $21^{\mathrm{a}}-22^{\underline{a}}$ semanas foram comparadas entre as três granjas.

\section{RESULTADOS E DISCUSSÃO}

Nas granjas A e B, nas quais os suínos foram seguidos no tempo, o comportamento sorológico foi semelhante, apesar de serem dois sistemas de produção diferentes (Tabela 1, Figura 1). Em ambas, a porcentagem de suínos soropositivos com duas semanas de idade foi alta $(85,9 \%$ na granja A e $91,3 \%$ na granja B), provavelmente devido ao estado imunológico das fêmeas (94,8\% das fêmeas soropositivas na granja A e 97,5\% das fêmeas soropositivas na granja B ao pós-parto (dados não mostrados) pelo esquema de vacinação utilizado. 
Tabela 1 - Positivos sobre total de amostrados (e porcentagem -\%-) para ELISA e nPCR nas diferentes amostragens nas distintas granjas, considerando as idades dos suínos nas granjas A, B e C.

\begin{tabular}{|c|c|c|c|c|c|}
\hline \multirow{3}{*}{ Granja } & \multirow{3}{*}{ Teste } & \multicolumn{4}{|c|}{---Idade (em semanas) - } \\
\hline & & & & & \\
\hline & & 2 & $8-10$ & 15 & $21-22$ \\
\hline \multirow{2}{*}{ A } & $\mathrm{nPCR}$ & $10 / 112 *(8,9)$ & $26 / 103(25,2)$ & $21 / 101 \div(20,8)$ & $17 / 99 \dagger(17)$ \\
\hline & ELISA & $92 / 107(85,9)$ & 19/95 (20) & 0/97 (0) & $2 / 100(2)$ \\
\hline \multirow{2}{*}{ B } & $\mathrm{nPCR}$ & $30 / 163 *(18,4)$ & $25 / 158(15,8)$ & $14 / 146 \ddagger(9,5)$ & $6 / 131(4,6)$ \\
\hline & ELISA & $148 / 162(91,3)$ & $69 / 155(44,5)$ & $1 / 144(0,7)$ & $3 / 129(2,3)$ \\
\hline \multirow{2}{*}{$\mathrm{C}$} & $\mathrm{nPCR}$ & - & - & - & $10 / 216 \dagger(4,6)$ \\
\hline & ELISA & - & - & - & $33 / 987(3,3)$ \\
\hline
\end{tabular}

* Diferença estatisticamente significativa $(\mathrm{P}=0,04)$

$\ddagger$ Diferença estatisticamente significativa $(\mathrm{P}=0,02)$

$\dagger$ Diferença estatisticamente significativa $(\mathrm{P}=0,05)$

Em ambos, houve um declínio no nível de anticorpos maternos na amostragem das 15 semanas de idade, sendo positivos ao ELISA 0/97 (0\%) dos animais na granja A e 1/144 (0,7\%) dos animais na granja B, em conformidade com estudos anteriores (JAYAPPA et al., 2001; CARRANZA et al., 2004) para a seguir, na amostragem das $21^{\underline{a}}-22^{\underline{a}}$ semanas aumentar levemente (dois reatores positivos na granja $\mathrm{A}$, e três reatores positivos na granja $\mathrm{B}$ ). Na granja $\mathrm{C}$, a porcentagem de soropositivos foi de 3,3\% (Tabela 1, Figura 1).

A baixa proporção de suínos soropositivos na fase de terminação nas três granjas e o fato de que na granja B (nas amostragens realizadas 11 e 16 meses após o desenvolvimento do programa de despovoamento parcial) não havia animais positivos indicam que a soroconversão foi mínima ou nula. Uma limitação deste estudo foi não amostrar animais com mais de 21-22 semanas de idade, para determinar finalmente se os animais teriam soroconvertido, mas, por razões de gestão e de marketing, não pôde ser feita a amostragem.

Os resultados do nPCR mostraram que o agente manteve-se após o desenvolvimento do programa de despovoamento parcial nas granjas A e B e depois da população inicial na granja C. A presença do DNA de $\boldsymbol{M}$. hyopneumoniae não indica uma infecção ativa e é impossível distingui-la de uma infecção assintomática (colonização). Neste caso em que a tosse não foi detectada, e a soroconversão e as lesões pulmonares foram mínimas, poderíamos afirmar que o agente se manteve, mas não em suficiente quantia para causar doença.

Quanto ao tipo de rebanho, detectaram-se comportamentos diferentes entre eles. Na granja A (partoterminação), houve picos de nPCR positivos (Figura 1). Isto pode ser devido a uma eliminação intermitente de
M. hyopneumoniae. O perfil obtido na granja B foi totalmente distinto, porque a porcentagem de suínos nPCR positivos diminuiu, semelhante ao padrão sorológico (Figura 1). Isso reforça a ideia de que sistemas de segregação de animais, juntamente com o tratamento antibiótico de forma pulsátil, sãoúteis para reduzir a carga bacteriana nas instalações e retardar a propagação do organismo.

Embora a amostragem utilizada não fosse calculada para detectar prevalência (mas pelo menos um positivo), a prevalência esperada seria igual ou superior a $8,9 \%$ na granja $A$, e igual ou superior a $18,4 \%$ na granja $\mathrm{B}$ (tendo diferença estatisticamente significativa entre ambas).

Neste estudo os resultados do nPCR observados em leitões com duas semanas de idade, pertencentes às granjas A e B, são importantes em dois sentidos. Por um lado, tem sido sugerido que a prevalência da colonização nasal de leitões pode ser um indicador da disseminação do M. hyopneumoniae pelas fêmeas (RUIZ et al., 2003) e isso é consistente com nossos resultados devido à cerca de $20 \%$ das fêmeas serem nPCR positivas ao pós-parto (dados não mostrados) e estas são, neste caso, a fonte mais provável de infecção, já que o ambiente tinha sido saneado, embora o agente possa ser transmitido pelo ar a mais de três kilômetros (THACKER, 2006). Por outro lado, também tem sido sugerido que a prevalência de leitões PCR positivos ao desmame pode ser utilizada para predizer a gravidade da doença em suínos na fase de crescimento-terminação (FANO et al., 2007) propondo que, nos estabelecimentos múltiplos-sítios, com uma prevalência inferior a $10 \%$, a gravidade da PES seria menor. No nosso caso, poderíamos dizer que ambos os rebanhos têm certamente mais de $10 \%$ de prevalência, mas, devido à terapia antibiótica, ao sistema all-in/all-out e à segregação em 


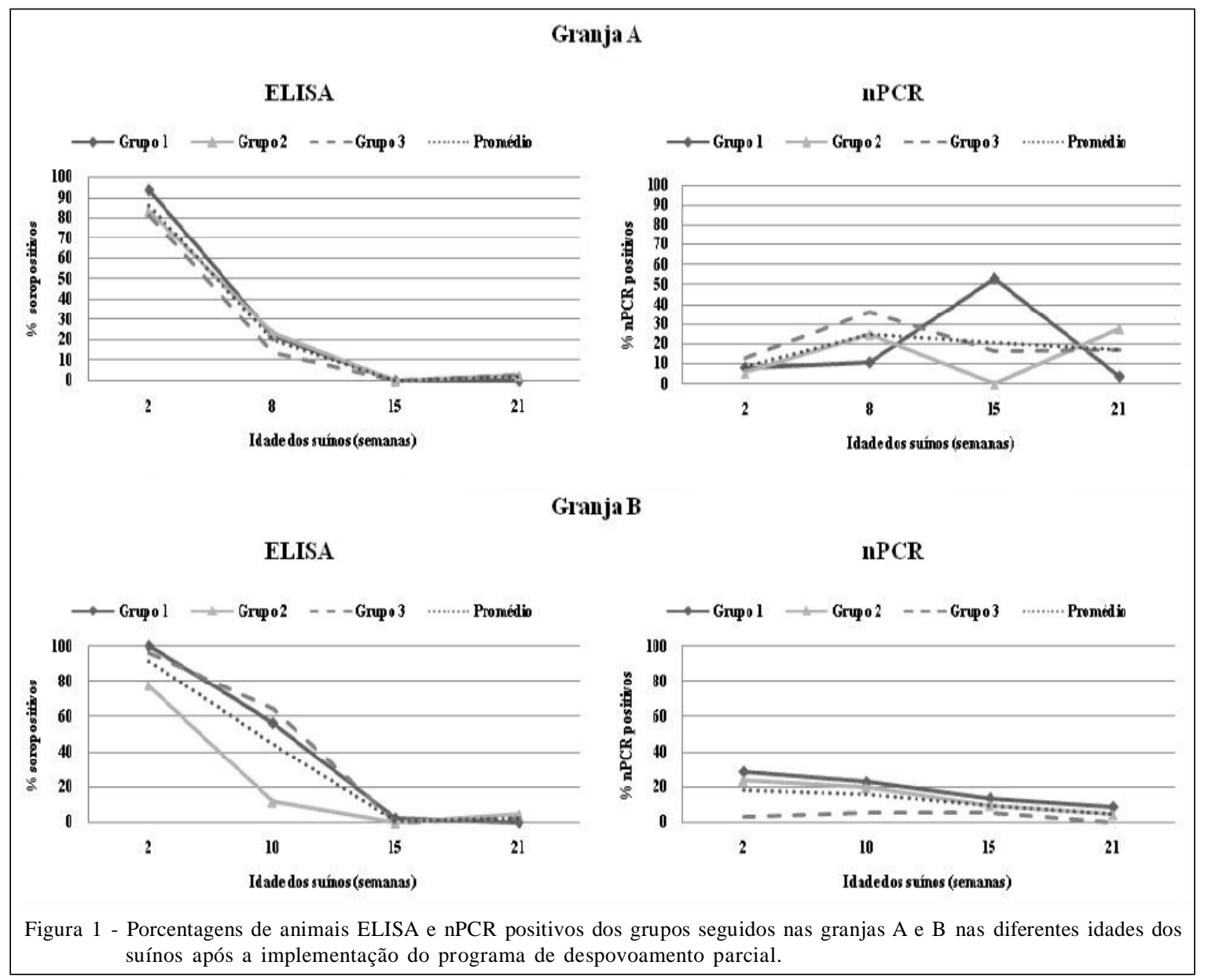

vários sítios na granja $\mathrm{B}$, as lesões pulmonares e a soroconversão foram mínimas, ou seja, foi minimizada a gravidade da PES.

Quanto às lesões microscópicas compatíveis com PES, as proporções foram as seguintes: $3 / 44(6,8 \%)$ na granja $\mathrm{A}, 3 / 36(8,3 \%)$ na granja $\mathrm{B}$. Na granja $\mathrm{C}$ não houve lesões compatíveis com PES. Na granja A e na granja B, dois pulmões mostraram lesões grau três e um mostrou típicas lesões pulmonares microscópicas (grau quatro): hiperplasia linfoplasmocitária perivascular e peribronquiolar, hiperplasia de pneumócitos tipo II, edema do espaço alveolar, o fluido com neutrófilos, macrófagos e plasmócitos, nódulos linfoides perivasculares e peribronquiais -hiperproliferação de tecido linfoide associado ao brônquio; BALT(CALSAMIGLIA et al., 2000).

As porcentagens de lesões microscópicas compatíveis com PES foram baixas se comparadas com aquelas encontradas antes do desenvolvimento do programa de despovoamento parcial (dados não publicados). Quando nós analisamos o percentual de suínos nPCR positivos nas 21ㄴ - 22a semanas com o percentual de lesões de pulmão, não há uma relação direta. Isso pode ser explicado porque o M. hyopneumoniae está presente no pulmão, apesar de não existir uma infecção (lesão inicial), ou há lesão, mas $\boldsymbol{M}$. hyopneumoniae não é detectado pelo nPCR, ou ainda pelo fato de que as lesões não são muito específicas, e outros agentes podem causar lesões similares, como vírus da gripe suína (THACKER et al., 2001) ou Circovírus porcino tipo 2 .

Com 15 semanas de idade, houve diferença estatisticamente significativa entre a proporção de nPCR positivos da granja Ae B. Com 21-22 semanas de idade, na granja $\mathrm{A}$, houve $17 \%$ de nPCR positivo, uma percentagem que é significativamente menor nas granjas $\mathrm{Be} \mathrm{C}$ (Tabela 1). Tudo isto pode sugerir um maior sucesso destes tipos de programas em granjas com segregação de animais.

Na granja $\mathrm{C}$, houve suínos nPCR positivos na fase de terminação, o que pode ser devido, embora o desmame tenha ocorrido entre os 7 e 9 dias de idade, a estes animais já serem portadores de M. hyopneumoniae ao ocupar as novas instalações. Isso significaria que o 
desmame precoce medicamentoso não é suficiente para prevenir a colonização de leitões. Estudos prévios de HARRIS (2000) demonstraram que, aplicando este método de desmame, a erradicaçãoe provável, mas nem sempre possível, apesar do tratamento antibiótico dos leitões e da imunização das fêmeas.

As baixas porcentagens de suínos soropositivos com 21-22 semanas de idade, em todos os casos, e as lesões macroscópicas e microscópicas compatíveis com a PES não são considerados como elementos suficientes para concluir que a PES não foi erradicada, pois não houve sinais clínicos (tosse), e as lesões podem ser causadas por outros agentes. Esta falta de provas é apoiada pelos resultados dos monitoramentos sorológicos realizados na granja $\mathrm{B}$, aos 11 e 16 meses após a aplicação do despovoamento parcial, visto que foram ambas as amostragens negativas. A utilização da PCR ao desmame permite a aplicação de algumas medidas que visam reduzir o impacto da doença em suínos nas fases de crescimento-terminação, poupando tempo em relação à sorologia e inspeção de lesões pulmonares, visto que, para executar essas técnicas de diagnóstico, deve-se esperar que os suínos atinjam o final da fase produtiva.

\section{CONCLUSÃO}

Nas condições deste estudo, $\boldsymbol{M}$. hyopneumoniae permaneceu nos estabelecimentos após implementação dos programas de controle/erradicação, mas em pequena quantidade para causar a doença. Destacamos o uso da PCR, ferramenta que deveria ser aplicada como técnica diagnóstica de rotina de monitoramento em programas de controle do agente. Os resultados da PCR podem ser aproveitados em complemento a outros instrumentos de diagnóstico, tais como a observação de sinais clínicos, sorologia e a inspeção da lesão pulmonar no abate neste tipo de monitoramento.

\section{REFÊRENCIAS}

ALFONSO, A. et al. Mycoplasma hyopneumoniae and PRRSv elimination in a 1700 sow multi-site system. In: IPVS CONGRESS, 18., 2004, Hamburg, Germany. Proceedings... Hamburg: IPVS, 2004. V.1, p.174.

BÆKBO P. et al. Eradication of Mycoplasma hyopneumoniae from infected herds without restocking. In: IPVS CONGRESS 13., 1994, Bangkok, Thailand. Proceedings... Bangkok: IPVS, 1994. p.135.

BÆKBO, P. Eradication of Mycoplasma hyopneumoniae and Actinobacillus pleuropneumoniae. In: COLLEGE OF VETERINARY MEDICINE. International symposium on swine disease eradication. St Paul, Minnesota: University of Minnesota, 2001. V.1, p.27-33.
CALSAMIGLIA, M. et al. Correlation between the presence of enzootic pneumonia lesions and detection of Mycoplasma hyopneumoniae in bronchial swabs by PCR. Veterinary Microbiology, v.76, p. 299-303, 2000. Disponível em: <http:/ / w w w. s c i e n c e d i r e c t . c o m/ science?_ob=ArticleURL\&_udi=B 6TD6-4135XCG$9 \& \_$user $=10 \&$ \&coverDate $=10 \% 2 \mathrm{~F} 01 \% 2 \mathrm{~F} 2000$ \&_rdoc $=1 \& \_\mathrm{fm}$ $\mathrm{t}=\mathrm{high} \&$ _orig $=$ search\&_origin $=$ search \&_sort $=\mathrm{d} \& \_$docanchor $=\&$ view $=c \& \_s e a r c h S t r I d=1625385728 \& \_$rerunOrigin $=$google $\& \_a c c t=C 00$ 0050221\&_version $=1 \&$ _urlVersion $=0$ \&_userid $=10 \& \mathrm{md} 5=66 \mathrm{c} 4 \mathrm{ba} 104 \mathrm{f}$ acb53ecdf9e8806f707c38\&searchtype $=\mathrm{a}>$. Acesso: 25 maio, 2005. doi: 10.1016/S0378-1135(00)00245-5.

CALSAMIGLIA, M. et al. Profiling Mycoplasma hyopneumoniae in farm using serology and a nested PCR technique. Journal of Swine Health and Production, v. 6, p. 263-268, 1999a. Disponível em: <http://www.aasv.org/shap/issues/v7n6/ v7n6p263.pdf>. Acesso em: 2 jun. 2005.

CALSAMIGLIA, M. et al. Applications of a nested- polymerase chain reaction assay to detect Mycoplasma hyopneumoniae from nasal swabs. Journal of Veterinary Diagnostic Investigation, v.1, p.246-251, 1999b. Disponível em: <http:/ /jvdi.org/cgi/content/abstract/11/3/246>. Acesso em: 23 set. 2000 .

CARRANZA, A. et al. Efecto de los anticuerpos pasivos y de la edad de los lechones en la vacunación contra Mycoplasma hyopneumoniae. Revista de la asociación de porcinocultura científica ANAPORC, v.1, n.8, p.45-51, 2004.

ERLANDSON K.R. et al. Evaluation of three serum antibody enzyme-linked immunosorbent assays for Mycoplasma hyopneumoniae. Journal of Swine Health and Production, v.13, n.4, p.198-203. 2005. Disponível em: <http:// www.aasv.org/shap/issues/v13n4/v13n4p198.pdf>. Acesso em: 6 maio, 2006.

FANO, E. et al. Effect of Mycoplasma hyopneumoniae colonization at weaning on disease severity in growing pigs. Canadian Journal of Veterinary Research. v.71, n.3, p.195200, 2007. Disponível em: <http://www.ncbi.nlm.nih.gov/pmc/ articles/PMC1899865/pdf/cjvr71_pg195.pdf〉. Acesso em: 14 out. 2008 .

HARRIS, D.L. Multi-site pig production. Ames: Iowa State University, 2000. 217p.

JAYAPPA, H. et al. Evaluation of the efficacy of Mycoplasma hyopneumoniae bacterin following immunization of young pigs in the presence of varying levels of maternal antibodies. In: AMERICAN ASSOCIATION SWINE VETERINARY ANNUAL MEETING, 2001, Nashville, Tennessee. Proceedings... Nashville: AASV, 2001. p.237-241.

KERN, D. et al. Exclusion of Mycoplasma hyopneumoniae infection in the offspring of seropositive gilts. In: AMERICAN ASOCIATION OF SWINE PRACTITIONERS, 1998, Nashville, Tennessee. Proceedings... Nashville: AASP, 1998. p.129131.

NIELSEN, E. et al. Attempted elimination of Actinobacillus pleuropneumoniae (serovar 2 and 6), Mycoplasma hyopneumoniae and PRRS-Ev by depopulation and tilmicosin treatment. In: IPVS CONGRESS, 17., 2002, Ames, Iowa, USA. Proceedings... Ames: IPVS, 2002. p.106. 
RUIZ, A. et al. Effect of Mycoplasma hyopneumoniae sow vaccination on piglets colonization at weaning. Journal of Swine Health and Production, v.11, n.3, p.131-135, 2003. Disponível em: <http://www.aasv.org/shap/issues/v11n3/ v11n3p131.pdf>. Acesso em: 15 maio, 2006.

SIBILA, M. et al. Dynamics of Mycoplasma hyopneumoniae infection in 12 farms with different production systems. Canadian Journal of Veterinary Research, v.68, n.1, p.1218, 2004. Disponível em: <http://www.ncbi.nlm.nih.gov/pmc/ articles/PMC1142124/pdf/cjvr68pg012.pdf>. Acesso em: $10 \mathrm{dez}$, 2006.

SMITH, W.; MORTIMER, I. Attempted eradication of Mycoplasma hyopneumoniae, Actinobacillus pleuropneumoniae and PRRS virus by segregated disease control (SDC) and tilmicosin treatment. In: IPVS CONGRESS, 16., 2000, Melbourne, Australia. Proceedings... Melbourne: IPVS, 2000. p.524.

SØRENSEN, K.J. et al. Evaluation of a blocking ELISA for screening of antibodies against porcine reproductive and respiratory syndrome (PRRS) virus. Veterinary Microbiology, v.56, n.1-2, p.1-8, 1997. Disponível em: <http://www.ncbi.nlm.nih.gov/ pubmed/9228677>. Acesso em: 15 jul. 2004.
THACKER E.L. Evaluation of diagnostic assays for Mycoplasma hyopneumoniae: Their potential role in eradication success - npb \#05-006. Pork Checkoff. National pork board, 2007. Disponível em: <http://www.pork.org/ ResearchDetail/484/Evaluationofdiagnost.aspx>. Online. Acesso em: em: 22 set. 2008.

THACKER, E. Mycoplasmal diseases. In: STRAW, B.E et al. (Eds.). Diseases of swine. 9.ed. Oxford: Blackwell Publishing, 2006. p.701-717.

THACKER, E.L. et al. Interaction between Mycoplasma hyopneumoniae and swine influenza virus. Journal of Clinical Microbiology, v.39, n.7, p.2525-2530, 2001. Disponível em: <http://jcm.asm.org/cgi/content/full/39/ 72525 ? view $=$ long \&pmid=11427564>. Acesso em: $15 \mathrm{fev}$. 2006. doi: 10.1128/JCM.39.7.2525-2530.2001.

THACKER, E.L. et al. Comparison of antibody production, lymphocyte stimulation and protection induced by four commercial Mycoplasma hyopneumonie bacterins. Journal of Swine heath and production, v.6, n.3, p.107-112, 1998. Disponível em: <https://www.aasv.org/shap/issues/v6n3/ v6n3p107.pdf>. Acesso em: 18 fev. 2006. 